\title{
Analysis of Indian Consumers' Behaviour using Lifestyle Segmentation
}

\author{
Reetika Jain \\ Associate Professor, Department of Commerce, Hansraj College, University of Delhi, Delhi - 110007, India; \\ reetikajain29@yahoo.com
}

\begin{abstract}
Demographic profiling has been an important basis of segmenting consumers. But the demographic variables provide a compartmentalised view of consumer behaviour. Purchase and consumption behaviour are in fact the result of influence of many variables operating simultaneously in the background. In order, to provide a holistic view of the 'why and how' of consumers purchase decision, lifestyle analysis has been considered a superior basis of customer profiling in recent research. Lifestyle study focuses on activities, interests and opinions of consumers and their role in formulating consumers' purchase decision. Past researches in India do provide an insight into the segmentation of Indian consumers on demographic and geographic basis. However, not much has been emphasised on the use of lifestyle for segmenting Indian consumers. The present research, therefore, tries to fill this void by providing the lifestyle profiling of the Indian consumers using factor analysis and cluster analysis. This study can help the marketers in segmenting their prospective and present customers using the suggested lifestyle dimensions.
\end{abstract}

Keywords: Consumer Profile, Indian Consumers, Lifestyle Dimensions, Segmentation

JEL classification: M31, M39

\section{Introduction}

In recent times, marketers have taken keen interest in studying the lifestyle patterns of consumers. Lifestyle study focuses on the everyday behaviour of consumers. Demographic studies, in contrast, present merely the demographic characteristics of consumers and are silent about their behavioural dimensions. Demographic variables provide a compartmentalised view of consumers' behaviour. They fail to give the holistic perspective of the consumer purchase behaviour. Purchase and consumption behaviour is in fact, the result of influence of many variables operating simultaneously in the background. In order to provide a holistic view of the 'why and how' of consumers purchase decision, lifestyle analysis has been considered a superior basis of customer profiling in recent research. Lifestyle study focuses on activities, interests and opinions of consumers and their role in formulating consumers' purchase decision.

Lifestyle or psychographics refer to an individual's way of living. Lifestyle segmentation research measures people's activities in terms of their - leisure time Activities, Interests, and Opinions (AIO) $)^{2,15,22}$.

- Activities such as work, leisure (sports and vacation behaviour), shopping habits, entertainment, membership in clubs, associations or community.

- Interests such as work, family, media consumption, eating habits, fashion.

- Opinions such as about oneself, politics, money and business, education, products, the future, social and cultural issues. 
This paper reviews the existing literature to identify the key lifestyle dimensions applicable in the Indian context. These dimensions were then tested for differences in lifestyle variables of Indian consumers using factor analysis and further were categorised into three clusters of Indian consumers. Thus, the present study provides classification of Indian consumers on the basis of their lifestyle and demographics. Such grouping of Indian consumers using cluster analysis provides relevant lifestyle segments that can be used by marketers in their targeting and positioning strategy.

Section 1 of the present paper introduces the lifestyle construct based on the review of past research. Section 2 gives a brief review of literature on lifestyle studies. Section 3 presents the objectives of the study in the form of proposed hypotheses. Section 4 throws light on the research design of the study and the profile of the respondents. The results of analysis are discussed in Section 5 followed by conclusion and limitations of the study in Section 6.

\section{Literature Review}

Bell ${ }^{2}$ introduced lifestyle concept for studying consumer behaviour. Lazer ${ }^{14}$ further refined the definition to narrow the conceptual and operational gap in the lifestyle research. Wells and Tigret $\underline{22}$ suggested application of lifestyle segmentation in marketing research. Plumer ${ }^{15}$ used the term psychographic for lifestyle studies as they combine the psychological and demographic variables in consumer studies and present a better picture of consumer decision-making to the marketer. Since then, lifestyle research has been widely used in consumer research internationally. Some such applications are in areas of retailing (Blackwell and Talarzyk) $)^{4}$, product management (Ahmed and Jackson) 1 , promotion and communication (Kaynak and Kara $)^{9}$, branding (Berry) ${ }^{3}$, service quality (Thompson and Kaminiski) $\frac{19}{}$, online marketing (Liu) $\frac{16}{}$, regiocentric studies (Harcar and Kaynak)

Researchers in India have also investigated the lifestyle pattern of Indian consumers on different aspects. Some of these researches are by $\operatorname{Kapur}^{\mathrm{Z}}$ (behaviour of two-wheeler owners), Shirali and Singh $\frac{18}{}$ (segmentation of Indian men), Jain and Dhingra ${ }^{6}$ (fashion lifestyles for segmenting young consumers in India), Verma and Hanspal ${ }^{20}$ (Profiling middle class consumers), Kumar and Mitra ${ }^{8}$ (brand choice), Roy and Goswami ${ }^{17}$ (purchase frequency of consumers), Krishnan ${ }^{11}$ (brand choice decision).

\section{Objectives of the Study and Hypotheses}

To understand the existing lifestyle dimensions of the Indian consumers and to identify the type of lifestyle characteristics possessed by these consumers, AIO statements obtained from marketing literature is used $\frac{12,9}{}$. The obtained dimensions are further analysed to segment the consumers into different clusters. So, the present study tests the following hypotheses:

$\mathrm{H}_{1}$ : Indian consumers differ in their lifestyle.

$\mathrm{H}_{2}$ : On the basis of differences in their lifestyle, the Indian consumers can be grouped into segments.

\section{Research Design}

The present study is based on a survey of Indian consumers. Consumers situated in Delhi and NCR area constitute the sample. The sample was selected on the basis of convenience sampling. In total 400 respondents were approached. The questionnaires were filled personally by approaching the respondents. Of the 400 questionnaires distributed, 283 usable questionnaires were ultimately received, constituting an overall response rate of 70.75 percent. The primary data in the form of the responses of the sampled units were collected through a structured and undisguised questionnaire which is divided into three sections. The questionnaire is based on the borrowed scale items from the studies by Kucukemiroglu ${ }^{12}$ and Kaynak and Kara ${ }^{10}$. Initially all the scale items used by the aforesaid researchers were listed. In order to make the questionnaire precise, clear, understandable and relevant, both to the Indian context and the present study, some items were deleted and few statements were modified. The final questionnaire was pre-tested on a sample of 20 respondents and the results were found to be positive. Finally, the questionnaire was administered on the remaining sample size. Part-A of the questionnaire contains multiple choice questions relating to the demographic description of the respondents. It studied the variables: age, gender, marital status, education, occupation, income and the frequency of overseas travel. Part-B of the questionnaire contains 51 five-point Likert-type statements to study lifestyle dimensions of Indian con- 
sumers. These statements were adapted from the work of Kaynak and $\operatorname{Kara}^{10}$. Further, to all the five-point type statements, another response category 'not applicable' was added to have the maximum response rate.

\subsection{Profile of the Respondents}

Table 1 presents the demographic characteristics of the respondents viz., age, gender, marital status, education, occupation, income, and overseas exposure. The age-wise distribution of the sample of 283 respondents shows that most of the respondents belong to the lower age groups. The gender-wise distribution of the sample is found to be uniform across males and females. Majority of respondents belong to the category of unmarried (74.5 percent). This is in conformity with the age-wise distribution of the sample, where young people (15-19 and 20-29 years age groups) accounted for 81.8 percent of the sample. Majority of the respondents have completed schooling (34.1 percent) or are graduates (40.8 percent). Thus, accounting for a total of 74.9 percent of the sample size. The occupational status of the respondents was categorised as student, employed, professional, business, retired, and house wife. Majority of the respondents were in the category of students (69.1 percent). Income dimension was studied as family monthly income rather than per capita income or annual income, which is more relevant in consumer market studies. It is found that most of the respondents belong to high income brackets, viz., family monthly income of more than ₹ 50,000 p.m. constituted 29.6 percent of sample size, income level of ₹ 30,00150,000 p.m. accounted for 27.4 percent, ₹ 20,001-30,000 p.m. constituted 21.3 percent, ₹ 10,001-20,000 p.m. constituted 14.6 percent and the income level of less than ₹ 10,000 p.m. accounted for 7 percent of the sample.

Table 1. Profile of Respondents

\begin{tabular}{|c|c|c|}
\hline \multicolumn{2}{|c|}{ Demographic Characteristic of Respondents } & Percentage \\
\hline \multirow[t]{6}{*}{ Age (years): } & $15-19$ & 45.2 \\
\hline & $20-29$ & 36.6 \\
\hline & $30-39$ & 3.8 \\
\hline & $40-49$ & 8.9 \\
\hline & $50-59$ & 3.8 \\
\hline & 60 and above & 1.6 \\
\hline \multirow[t]{2}{*}{ Gender: } & Male & 52.9 \\
\hline & Female & 47.1 \\
\hline \multirow[t]{3}{*}{ Marital Status: } & Married & 20.7 \\
\hline & Unmarried & 74.5 \\
\hline & Single (Divorced/Widowed) & 4.8 \\
\hline
\end{tabular}

\begin{tabular}{|ll|c|}
\hline Education: & Secondary & 3.8 \\
& Senior Secondary & 34.1 \\
& Graduate & 40.8 \\
& Post-graduate & 11.1 \\
& Professional Qualification & 10.2 \\
\hline Occupation: & Student & 69.1 \\
& Employed & 16.6 \\
& Professional & 6.1 \\
& Business & 3.2 \\
& Retired & 1.3 \\
& Housewife & 3.8 \\
\hline Income Level: & Less than ₹ 10,000 p.m. & 7.0 \\
₹10,000 p.m. - & ₹ 20,000 p.m. & 14.6 \\
₹ 20,001 p.m. - ₹ 30,000 p.m. & 21.3 \\
₹ 30,001 p.m. - ₹ 50,000 p.m. & 27.4 \\
More than ₹ 50,000 p.m. & 29.6 \\
\hline
\end{tabular}

\section{Results and Analysis}

Section B of the questionnaire had 51 statements that studied the lifestyle characteristics of Indian consumers. Factor analysis was performed to identify the lifestyle dimensions. The result of factor analysis is given in Table 2. Bartlett's test of sphericity gives the approximate chisquare statistics as 3.388 which is significant at 0.05 level, thus indicating that the variables are correlated in the population. The value of the Kaiser-Meyer-Olkin measure of sampling adequacy (KMO-statistic) is 0.63 and is also significant as it is above the threshold limit of 0.50 . Thus, factor analysis is considered an appropriate technique for analysing the correlation matrix of variables. Method of a principal component analysis, scree plot and a priori methods were used in tandem to determine minimum number of factors that will account for maximum variance in the data.

Table 2. KMO and Bartlett's Test

\begin{tabular}{|c|c|c|}
\hline $\begin{array}{c}\text { Kaiser-Meyer-Olkin Measure of Sampling } \\
\text { Adequacy. }\end{array}$ & .630 \\
\hline $\begin{array}{c}\text { Bartlett's Test of } \\
\text { Sphericity }\end{array}$ & Chi-Square Statistic & 3.388 \\
\hline & Df & 1275 \\
\hline & p-value & .000 \\
\hline
\end{tabular}

Principal Component analysis method (Table 3) resulted in 12 factors that explained 50.148 percent of variance. Only those factors with eigen values significantly greater than one was retained. Even the scree plot $^{a}$ (Figure 1) shows screes in the curve till twelfth factor after 


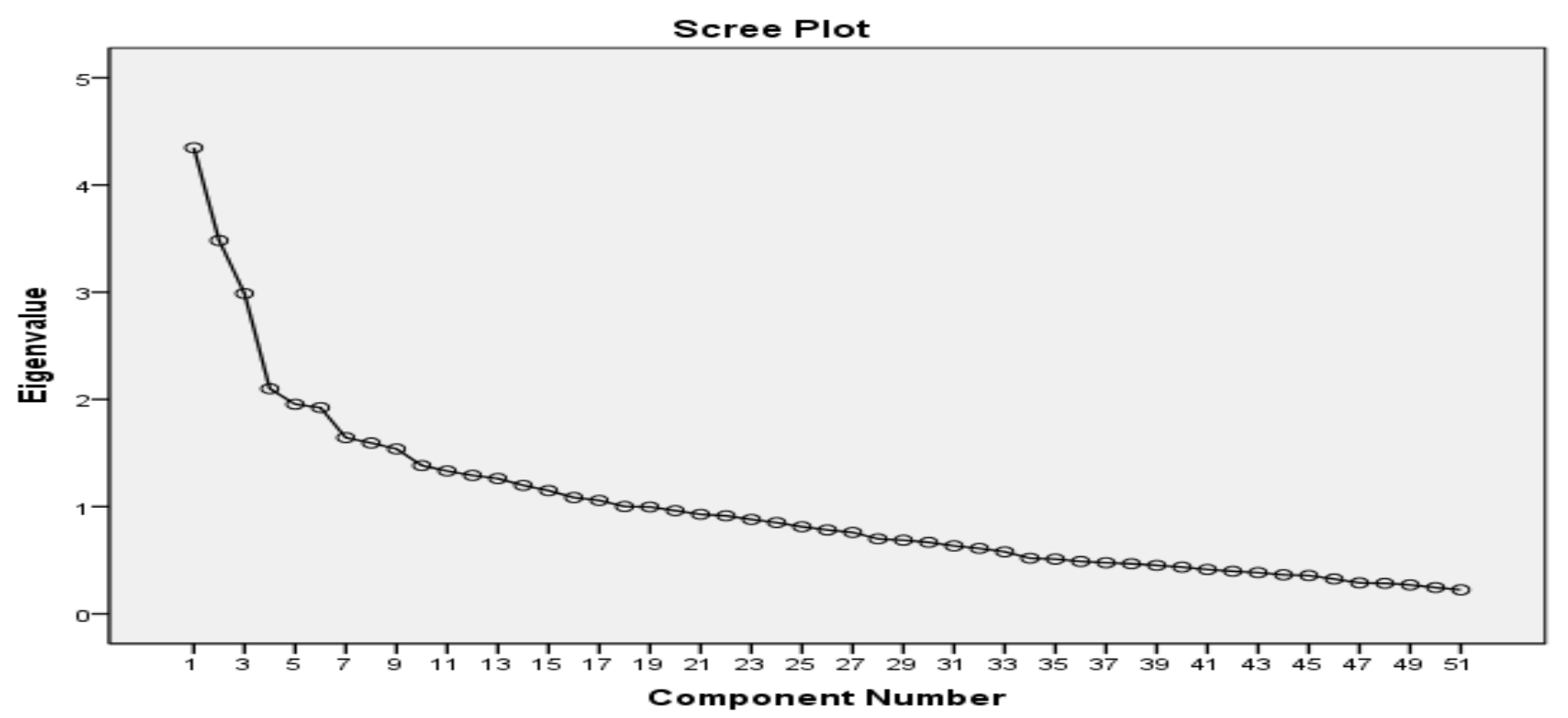

Figure 1. Scree plot.

which the curve is smooth. These twelve factors were then rotated using varimax procedure in order to minimize the number of variables with high loading on a factor, thereby enhancing the interpretability of the factor. Factor 1 was labelled 'group-oriented factor' and explained 5.75 percent of variance. Factors 2, 3, 4, 5 and 6 were labelled 'leadership factor', 'hygiene factor', 'family-oriented factor', 'inward-oriented factor' and 'health-conscious factor' respectively. They accounted for 4.89, 4.58, 4.4, 4.27 and 4.2 percent of variance respectively. Factors 7 and 8 accounted for 4.12 percent and 4.09 percent of variance respectively. They were labelled 'independent factor' and 'community-oriented factor' respectively. Finally, factors $9,10,11$ and 12 were referred as 'cost-conscious factor', 'outwards-oriented factor', 'conservative factor' and 'adventurous factor' and these explained 3.91, 3.41, 3.37 and 3.17 percent of variance respectively.

Factor loading (Table 4) results show correlation between lifestyle statements and the 12 lifestyle dimensions. AIO statements 1, 2, 3, 4, 5, 16, 14 have loading score of more than 0.4 with Factor 1 (group-oriented factor). Lifestyle statements $25,8,35,49,19$ have high loading score $(>0.40)$ with factor 2 (leadership factor). Statements $40,36,34,33,37$ have high loading $(>0.40)$ with factor 3 (hygiene factor). AIO statements 23, 22, 18, 24, 21 have good loading $(>0.40)$ with factor 4 (family-oriented factor), Lifestyle statements 7, 6, 47 have high loading score $(>0.40)$ with factor 5 (inward-oriented factor). Lifestyle statements
Table 3. Variance Explained by Factors on Using Factor Analysis

\begin{tabular}{|c|c|c|c|}
\hline \multirow{2}{*}{ Component } & \multicolumn{3}{|c|}{ Rotation Sums of Squared Loadings } \\
\cline { 2 - 4 } & Total & \% of Variance & Cumulative \% \\
\hline 1 & 2.933 & 5.751 & 5.751 \\
\hline 2 & 2.491 & 4.885 & 10.636 \\
\hline 3 & 2.334 & 4.577 & 15.213 \\
\hline 4 & 2.242 & 4.396 & 19.609 \\
\hline 5 & 2.177 & 4.268 & 23.876 \\
\hline 6 & 2.142 & 4.200 & 28.076 \\
\hline 7 & 2.100 & 4.118 & 32.194 \\
\hline 8 & 2.086 & 4.090 & 36.285 \\
\hline 9 & 1.995 & 3.911 & 40.196 \\
\hline 10 & 1.739 & 3.411 & 43.606 \\
\hline 11 & 1.718 & 3.369 & 46.975 \\
\hline 12 & 1.618 & 3.173 & 50.148 \\
\hline
\end{tabular}

Extraction Method: Based on Principal Component Analysis.

$29,28,51$ have high loading score $(>0.40)$ with factor 6 (health-conscious factor). Lifestyle statements 12, 11, 13 have high loading score $(>0.40)$ with factor 7 (independent factor). Lifestyle statements $38,39,41,42$ have high loading score $(>0.40)$ with factor 8 (community-oriented factor). Lifestyle statements $44,45,50$ have high loading score (>0.40) with factor 9 (cost-conscious factor). Lifestyle statements 27,32 have high loading score $(>0.40)$ with factor 10 (outward-oriented factor). Lifestyle statements 10 , 
Table 4. Factor Loading Rotated Component Matrix

\begin{tabular}{|c|c|c|c|c|c|c|c|c|c|c|c|c|}
\hline & \multicolumn{12}{|c|}{ Component } \\
\hline & 1 & 2 & 3 & 4 & 5 & 6 & 7 & 8 & 9 & 10 & 11 & 12 \\
\hline Lifestyle3 & .700 & .046 & .025 & .140 & -.049 & -.053 & .019 & -.021 & -.109 & .062 & .083 & .121 \\
\hline Lifestyle4 & .611 & .207 & -.043 & -.048 & .062 & .099 & -.076 & .168 & -.109 & -.028 & -.180 & .189 \\
\hline Lifestyle1 & .581 & .043 & -.031 & .018 & .099 & .006 & .033 & .086 & .243 & -.003 & .122 & -.180 \\
\hline Lifestyle2 & .567 & -.039 & -.224 & -.275 & -.063 & .278 & -.161 & .067 & -.030 & -.035 & .064 & .019 \\
\hline Lifestyle5 & .468 & .220 & -.011 & -.044 & -.295 & .089 & -.015 & .221 & -.033 & .072 & -.031 & -.340 \\
\hline Lifestyle26 & .445 & .031 & -.032 & .158 & -.178 & -.112 & -.036 & -.138 & .138 & .441 & -.148 & -.230 \\
\hline Lifestyle16 & .460 & .221 & .044 & -.020 & -.312 & .353 & -.151 & -.252 & .113 & -.194 & -.061 & -.164 \\
\hline Lifestyle14 & .456 & .165 & .156 & -.022 & -.189 & -.021 & .310 & -.008 & .011 & -.292 & .065 & -.318 \\
\hline Lifestyle25 & .051 & .648 & -.129 & .091 & .011 & .106 & -.071 & -.017 & .155 & .167 & -.156 & -.099 \\
\hline Lifestyle8 & .150 & .627 & -.027 & -.027 & .046 & .031 & .220 & .165 & .029 & -.111 & .160 & -.081 \\
\hline Lifestyle35 & -.053 & .469 & .393 & .024 & .227 & .024 & -.157 & .058 & .169 & .189 & .130 & .154 \\
\hline Lifestyle 49 & .019 & .451 & .165 & .001 & -.126 & .015 & -.039 & -.302 & .022 & .091 & .199 & -.008 \\
\hline Lifestyle19 & .109 & .449 & .070 & -.044 & -.075 & .146 & .241 & .008 & .076 & -.134 & -.057 & .166 \\
\hline Lifestyle9 & .143 & .443 & -.125 & -.187 & -.021 & .419 & .057 & .095 & -.168 & .094 & -.180 & .116 \\
\hline Lifestyle46 & .152 & .287 & -.130 & -.220 & -.080 & .233 & -.100 & -.215 & .106 & .042 & .089 & .253 \\
\hline Lifestyle 40 & -.075 & .066 & .606 & .137 & .068 & .095 & .004 & .258 & -.144 & .089 & -.009 & .048 \\
\hline Lifestyle36 & -.056 & .047 & .533 & .178 & -.024 & .008 & .005 & -.035 & .204 & .172 & -.116 & .255 \\
\hline Lifestyle34 & .107 & .191 & .528 & .043 & .162 & .233 & .192 & -.032 & .157 & -.196 & -.022 & -.059 \\
\hline Lifestyle15 & .422 & .047 & .496 & -.060 & -.072 & -.242 & .088 & -.102 & .117 & -.067 & .047 & .176 \\
\hline Lifestyle33 & .241 & .204 & -.488 & .059 & .052 & -.062 & .117 & .115 & -.183 & -.084 & .066 & .165 \\
\hline Lifestyle37 & -.021 & -.122 & .475 & .107 & .048 & -.046 & .090 & .182 & -.096 & .028 & .091 & -.021 \\
\hline Lifestyle23 & -.004 & -.041 & .181 & .695 & .129 & -.060 & -.047 & .108 & -.025 & -.109 & -.011 & -.002 \\
\hline Lifestyle22 & -.029 & -.131 & .030 & .689 & -.017 & -.136 & .101 & .025 & .240 & .084 & -.186 & -.031 \\
\hline Lifestyle18 & -.034 & .064 & -.003 & .516 & -.338 & .269 & .119 & -.091 & .029 & .227 & .149 & .113 \\
\hline Lifestyle24 & .061 & .334 & .144 & .455 & .250 & -.023 & -.004 & .076 & -.278 & .059 & .045 & -.072 \\
\hline Lifestyle21 & .257 & .140 & .100 & .479 & .039 & -.239 & .144 & .070 & .206 & .006 & .010 & .263 \\
\hline Lifestyle7 & -.046 & .058 & .126 & .117 & .773 & .130 & -.044 & -.009 & .059 & .083 & -.060 & -.050 \\
\hline Lifestyle6 & .003 & -.082 & -.039 & .051 & .711 & .037 & .056 & -.083 & .026 & -.167 & .142 & .066 \\
\hline Lifestyle47 & -.009 & .053 & .182 & -.217 & .364 & .201 & .079 & .027 & .232 & -.116 & -.056 & .038 \\
\hline Lifestyle29 & .013 & .067 & .007 & -.071 & .035 & .651 & .058 & .030 & -.035 & .006 & -.086 & .212 \\
\hline
\end{tabular}




\begin{tabular}{|c|c|c|c|c|c|c|c|c|c|c|c|c|}
\hline Lifestyle28 & .041 & .140 & .217 & -.071 & .147 & .559 & .068 & -.049 & -.088 & -.043 & .063 & -.108 \\
\hline Lifestyle51 & -.130 & .011 & -.036 & .094 & .169 & .429 & -.086 & .089 & .089 & -.426 & -.155 & .317 \\
\hline Lifestyle30 & .492 & -.003 & -.100 & .022 & .284 & .402 & .114 & .088 & .068 & .081 & .163 & .071 \\
\hline Lifestyle12 & -.015 & -.027 & .096 & .073 & .029 & .078 & .765 & .032 & -.053 & .000 & .045 & -.001 \\
\hline Lifestyle11 & -.020 & .166 & -.012 & -.019 & .083 & -.013 & .712 & .102 & .095 & .045 & .001 & .112 \\
\hline Lifestyle13 & -.083 & -.002 & .071 & .136 & -.127 & .079 & .520 & .062 & .389 & .073 & -.051 & -.174 \\
\hline Lifestyle39 & -.035 & -.102 & .014 & .101 & -.104 & -.028 & -.010 & .663 & -.046 & -.121 & -.047 & -.112 \\
\hline Lifestyle 42 & .038 & .132 & -.036 & -.023 & -.062 & .098 & .126 & .616 & -.042 & .049 & .076 & .103 \\
\hline Lifestyle38 & .169 & .033 & .141 & .071 & .015 & .061 & -.002 & .600 & .153 & -.028 & -.084 & .099 \\
\hline Lifestyle41 & .080 & .008 & .174 & -.042 & .111 & -.144 & .064 & .466 & .156 & .211 & .071 & -.005 \\
\hline Lifestyle48 & -.012 & .048 & .148 & .005 & .058 & -.019 & .174 & .030 & .595 & -.084 & -.111 & -.036 \\
\hline Lifestyle 45 & .114 & -.006 & -.002 & -.129 & .151 & -.055 & .013 & .159 & .507 & .064 & .380 & .211 \\
\hline Lifestyle 44 & .080 & .180 & -.147 & .066 & .008 & .049 & -.023 & .137 & .498 & .050 & .368 & .068 \\
\hline Lifestyle 50 & -.028 & .079 & .043 & .298 & .057 & -.140 & -.085 & -.084 & .491 & .139 & -.113 & -.079 \\
\hline Lifestyle27 & -.001 & .122 & .124 & .040 & -.062 & -.010 & .051 & .055 & .012 & .690 & .031 & .036 \\
\hline Lifestyle17 & .132 & -.127 & -.100 & .462 & -.322 & .083 & .268 & .091 & .039 & .478 & .292 & -.045 \\
\hline Lifestyle32 & .114 & .294 & -.198 & -.014 & -.083 & -.126 & .256 & .043 & -.102 & -.429 & .136 & .152 \\
\hline Lifestyle10 & .133 & .180 & .037 & -.003 & -.017 & .123 & .007 & .110 & .053 & -.063 & -.636 & .162 \\
\hline Lifestyle20 & .166 & .236 & .047 & -.086 & .052 & .017 & .070 & -.006 & -.036 & -.027 & .570 & .052 \\
\hline Lifestyle 43 & .088 & .059 & .102 & .023 & -.142 & .289 & -.273 & .244 & .211 & -.246 & .470 & -.023 \\
\hline Lifestyle31 & .039 & .031 & .113 & .003 & -.001 & .167 & .047 & .078 & -.037 & -.060 & -.042 & .719 \\
\hline
\end{tabular}

Extraction Method: Based on Principal Component Analysis.

Rotation Method: Based on Varimax with Kaiser Normalization.

20, 43 have high loading score $(>0.40)$ with factor 11 (conservative factor). Lifestyle statements 31 have high loading score (>0.40) with factor 12 (adventurous factor). Lifestyle statement 46 is not significantly loading with any of the factors. Hence, this statement is removed from further analysis. Also, statements 26, 9, 15, 30, 17 are loading on more than one factors, therefore, are also removed. From the above analysis, it is proved that Indian consumers differ in their lifestyles. Therefore, our analysis is consistent with hypothesis $\mathrm{H}_{1}$.

After identifying the lifestyle factors, these factors were classified in appropriate segments using cluster analysis. On running cluster analysis, three clusters emerged (Table 5). In the next stage, lifestyle factors were designated to the appropriate cluster using $\mathrm{k}$ mean clustering
(Table 6). ANOVA results (Table 7) show that except for three lifestyle factors viz., family-oriented factor, inward -oriented factor and adventurous factor, all others were significantly related to the allocated cluster groups. Thus, our analysis lends support to hypothesis $\mathrm{H}_{2}$.

Table 5. Number of Cases in Each Cluster

\begin{tabular}{|c|c|c|}
\hline Cluster & 1 & 17 \\
\cline { 2 - 3 } & 2 & 178 \\
\cline { 2 - 3 } & 3 & 88 \\
\hline \multicolumn{2}{|c|}{ Valid Cases } & 283 \\
\hline
\end{tabular}

Cluster 1 has lifestyle dimensions categorised as grouporiented, conservative and outward-oriented. These are 
largely students who are dependent on their parents for finances. Hence, they can be called Nesters, ready to fly.

Cluster 2 has lifestyle dimensions categorised as leadership, hygiene, health-conscious and independent factors. They are well-educated, well-off and settled in life. So, they can be called Opinion leaders.

Cluster 3 has lifestyle dimensions viz., community orientation and cost-conscious factors. They are educated and have reasonable income levels. They can therefore, be called Collectivists seeking value for money.

\section{Conclusion and Limitations of the Study}

Lifestyle studies enables classification of consumers' behaviour with respect to all areas of life. This further allows grouping of consumers using cluster analysis to produce relevant lifestyle segments ${ }^{13}$. The present study is a step in this direction. Lifestyle statements adapted from the past research were factor analysed. This resulted in 12 prominent lifestyle dimensions for Indian consumers viz., 'group-oriented factor', 'leadership factor', 'hygiene factor', 'family-oriented factor', 'inward-oriented factor', 'health-conscious factor', 'independent factor', 'community-oriented factor', 'cost-conscious factor', 'outwards-oriented factor', 'conservative factor' and 'adventurous factor'. The labels to these factors point towards the key focus of the Indian consumers in their day-to-day lives as reflected in their AIO.

Table 6. Cluster Membership

\begin{tabular}{|c|c|}
\hline Case & 3 Clusters \\
\hline Group-oriented factor & 1 \\
\hline Leadership factor & 2 \\
\hline Hygiene factor & 2 \\
\hline Family-oriented factor & 3 \\
\hline Inward-oriented factor & 1 \\
\hline Health-conscious factor & 2 \\
\hline Independent factor & 2 \\
\hline Community-oriented factor & 3 \\
\hline Cost-conscious factor & 3 \\
\hline Outward-oriented factor & 1 \\
\hline Conservative factor & 1 \\
\hline Adventurous factor & 3 \\
\hline
\end{tabular}

Note: 1, 2, 3 denote clusters namely, Nesters, ready to fly; Opinion leaders; Collectivists seeking value for money respectively.
Cluster analysis was applied to the above lifestyle factors. Three clusters emerged for segmenting Indian consumers on the basis of demographic and lifestyle variables. Cluster 1 comprised young people having no overseas exposure. They were group-oriented, outwardoriented and conservative consumers. This cluster was therefore, labelled as 'Nesters, ready to fly' as at this stage they are influenced by peers and parents but eventually make their own decisions. Marketers can target these young minds with products that show emotional bondage with family members or friends. This can help in getting their acceptance for the product.

\section{Table 7. ANOVA Results of Cluster Analysis}

\begin{tabular}{|c|c|c|c|c|c|c|}
\hline & \multicolumn{2}{|c|}{ Cluster } & \multicolumn{2}{c|}{ Error } & \\
\cline { 2 - 6 } & $\begin{array}{c}\text { Mean } \\
\text { Square }\end{array}$ & Df & $\begin{array}{c}\text { Mean } \\
\text { Square }\end{array}$ & Df & $\begin{array}{c}\text { F- } \\
\text { Statistic }\end{array}$ & $\begin{array}{c}\text { p- } \\
\text { value }\end{array}$ \\
\hline $\begin{array}{c}\text { Group- } \\
\text { oriented } \\
\text { factor }\end{array}$ & 14.284 & 2 & .857 & 279 & 16.664 & .000 \\
\hline $\begin{array}{c}\text { Leadership } \\
\text { factor }\end{array}$ & 8.913 & 2 & .915 & 279 & 9.742 & .000 \\
\hline $\begin{array}{c}\text { Hygiene } \\
\text { factor }\end{array}$ & 5.208 & 2 & .955 & 279 & 5.455 & .001 \\
\hline $\begin{array}{c}\text { Family- } \\
\text { oriented } \\
\text { factor }\end{array}$ & 1.440 & 2 & .995 & 279 & 1.447 & .229 \\
\hline $\begin{array}{c}\text { Inward- } \\
\text { oriented } \\
\text { factor }\end{array}$ & 1.130 & 2 & .999 & 279 & 1.131 & .337 \\
\hline $\begin{array}{c}\text { Health- } \\
\text { conscious } \\
\text { factor }\end{array}$ & 13.842 & 2 & .862 & 279 & 16.059 & .000 \\
\hline $\begin{array}{c}\text { Independent } \\
\text { factor }\end{array}$ & 9.768 & 2 & .906 & 279 & 10.784 & .000 \\
\hline $\begin{array}{c}\text { Community- } \\
\text { oriented } \\
\text { factor }\end{array}$ & 8.551 & 2 & .919 & 279 & 9.307 & .000 \\
\hline $\begin{array}{c}\text { Cost- } \\
\text { fonscious } \\
\text { factor }\end{array}$ & 18.481 & 2 & .812 & 279 & 22.759 & .000 \\
\hline $\begin{array}{c}\text { Outward- } \\
\text { oriented } \\
\text { factor }\end{array}$ & 3.214 & 2 & .976 & 279 & 3.292 & .021 \\
\hline $\begin{array}{c}\text { Conservative } \\
\text { factor }\end{array}$ & 5.688 & 2 & .950 & 279 & 5.990 & .001 \\
\hline
\end{tabular}


Cluster 2 consists of consumers who are well-educated, well-off and settled in life. They were also characterised as being healthy, hygiene-conscious, independent decisionmaker and possessing leadership skills. This cluster was therefore, called 'Opinion leaders'. Marketers can target these consumers with innovative products or health and fitness products or products with new and modified uses. These consumers can act as endorsers of these products to the remaining market.

Finally, Cluster 3 are consumers who are educated but with reasonable income level. As a result, they are costconscious consumers. At the same time, they are socially engaged and involved in community activities. They are therefore, labelled as 'Collectivists seeking value for money'. Marketers can target this market with products that ensure community or country welfare (products that highlight 'Made in India' label) or are priced modestly. The lifestyle concept has thus, become the core to segmentation research ${ }^{21}$. Marketing managers can adapt their marketing strategies viz., targeting, positioning, branding, media communication, retailing strategies to the changing lifestyle patterns. Lifestyle data are very useful in market segmentation and in developing country-specific marketing strategy, yet marketers need to be cautious while using lifestyle variables in their studies, as these variables are not as stable as demographic variables.

There are some limitations specific to the present study. Firstly, the study is confined to consumers located in Delhi-NCR. Secondly, the data was obtained using convenience sampling, and hence does not provide adequate representation of all age groups. Further, a larger sample is recommended for a more conclusive study. Future research in this area can examine the influence of lifestyle dimensions on brand choice, product choice and store choice behaviour of Indian consumers.

\section{References}

1. Ahmed SA, Jackson DN. Psychographics and public policy decisions: Welfare assistance. J Consum Res. 1979; 5:22939. https://doi.org/10.1086/208735

2. Bell WB. Social choice, lifestyle, and suburbal residence, in Rhe Suburban Community. William M Dobriner, ed. New York: G.P. Putnam's Sons; 1958. p. 225-42.

3. Berry EJ. Ads enlist ambiguity to target varied lifestyles, values. Ad Forum. 1983; 4:10-1.
4. Blackwell RD, Talarzyk WW. Lifestyle retailing: Competitive strategies for the 80's. Journal of Retailing. 1983; 59:7-27.

5. Harcar T, Kaynak E. Lifestyle orientation of US and Canadian consumers: Are regio-centric standardized marketing strategies feasible? Asia Pacific Journal of Marketing and Logistics. 2007; 20(4):433-54. https://doi. org/10.1108/13555850810909740

6. Jain SK, Surabhi D. Fashion lifestyle and market segmentation: A multivariate analysis. Management and Change. 1999; 3(2):99-118.

7. Kapur S. Lifestyle on Two Wheels. Buiness World. 1995.

8. Kumar RV, Mitra S. Toothpaste usage and consumption profile. Organizational Management. 2004; XX:5-11.

9. Kaynak E, Kara A. Consumer lifestyle and ethnocentrism: A comparative study in Kyrgyzstan and Azarbaijan. Istanbul 49th Esomar Congress Proceedings; 1996. p. 577-96.

10. Kaynak E, Kara A. Consumer perception of foreign products - an analysis of product-country images and ethnocentrism. Eur. J. Mark. 2002; 36(7/8):928-49. https://doi. org/10.1108/03090560210430881

11. Krishnan J. Lifestyle: A tool for understanding buyer behaviour. Int Journal of Economics and Management. 2011; 5(1):283-98.

12. Kucukemiroglu O, Harcar T, Spillan JE. Market segmentation by exploring buyer lifestyle dimensions and ethnocentrism among Vietnamese consumers: An empirical study. Journal of Asia-Pacific Business. 2007; 7:4:55-76. https://doi.org/10.1300/J098v07n04_04

13. Lawson R, Todd S. Consumer lifestyles: A social stratification perspective. Marketing Theory. 2002; 2(3):295-307. https://doi.org/10.1177/1470593102002003278

14. Lazer W. Symbolism and lifestyle in toward scientific marketing. Stephen A. Greyser, Ed. Chicago: American Marketing Association; 1963; II:140-9.

15. Plummer JT. The concept and application of lifestyle segmentation. J. Mark. 1974; 38:33-7. https://doi.org/10.2307/1250164

16. Liu Y. Developing a scale to measure the interactivity of web sites. J Advertising Res. 2003; 43(6):207-16. https:// doi.org/10.2501/JAR-43-2-207-216

17. Roy S, Goswami P. Psychographics and its effect on purchase frequency - A study on college goers of Kolkota, India. Journal of Indian Institute of Management, Calcutta. 2007; 34:63-93.

18. Shirali A, Singh I. Status symbols an A and M, ORG-MAR G Survey. Advertising and Marketing; 1997. p. 36-54.

19. Thompson AM, Kaminski PF. Psychographic and lifestyle antecedents of service quality expectations. J. Serv. Mark. 1993; 7(4):53-61. https://doi. org/10.1108/08876049310047742 
20. Verma DPS, Hanspal S. Influence if lifestyles on consumers' buying behaviour. Paradigm. 2000; 4(2):52-65. https://doi. org/10.1177/0971890720000207

21. Vyncke P. Lifestyle segmentation: From attitudes, interests and opinions, to values, aesthetic styles, life visions and media preferences. Eur. J. Commun. 2002 Dec; 17(4):44563. https://doi.org/10.1177/02673231020170040301

22. Wells WD, Tigert DJ. Attitudes, interests and opinions. J Advert Res. 1971; 11:27-35.

\section{Note}

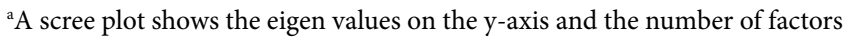
on the $\mathrm{x}$-axis. It always displays a downward curve. The point where the slope of the curve is clearly leveling off indicates the number of factors that should be generated by the factor analysis. 